\title{
Clinical Outcome of En-Bloc Resection of Distal Radius Giant Cell Tumor And Reconstruction by Non Ascularized Fibular Graft \&Transossious Augmentation of Wrist By PalmarishLongusTendon,An Improvise Technique
}

\author{
Dr SaikatSau. Ms-Orthopaedics ${ }^{1,}$ Dr Chinmay Biswas ${ }^{2}$ \\ ${ }^{1}$ Senior Resident.Sskm Hospital \\ ${ }^{2}$ Dnb-Orthopaesics,Assistant Prof.Bankura Medical College \& Hospital
}

\begin{abstract}
:
Introduction: Giant cell tumor (GCT) of bone is a benign but locally aggressive tumor with tendency for local recurrence. Usually it can be treated by en-bloc resection and reconstruction arthroplasty using autogenous non-vascularizedipsilateral proximal fibular graft. Fibulo-carpal subluxation can be prevent by transossiouspamarishlongus tendon. This improvise technique found useful in preserving the movements and functions as well as stability of the wrist.

Materials and Methods: Ten patients with a mean age of 33 years, witheither Campanacci grade II or III histologically proven giant cell tumours of lower end radiuswere treated with wide excision and reconstruction with ipsilateral non-vascularised proximalfibularautograft. Host graft junction was fixed with dynamic compression plate $(D C P)$ in allcases. Wrist ligament reconstruction and fixation of the head of the fibula with carpal bonesand distal end of the ulna using $K$-wires along with pamarishlongus tendon reinforcement throw transeossiciousroot and primary cancellous iliac crest grafting at grafthost junction was done in all cases.

Results: The follow-up ranged from 30 to 60 months (mean,46.8). At last follow-up, the average combined range of motion was $100^{\circ}$ with range varyingfrom $60^{\circ}$ to $125^{\circ}$. The average union time was 7 months (range, 4 to 12). Non-union occurredin 1 case. Graft resorption occurred in another case. Localised soft tissue recurrence occurredin another case after 3 years and was treated by excision. There was no case of graft fracture,metastasis, death, local recurrence or signifi cant donor site morbidity. A total of 3 secondaryprocedures were required.

Conclusions: Enbloc resection of giant cell tumours of the lowerend radius is a widely accepted method. Reconstruction with non-vascularised fibular graft,internal fixation with DCP with primary corticocancellous bone grafting with transfixation of the fibular head and wrist ligament reconstruction minimises the problem and gives satisfactoryfunctional results.
\end{abstract}

Keywords: Giant cell tumor, distal radius, en-bloc resection, reconstruction arthroplasty, proximal, fibular graft

\section{Introduction}

Giant cell tumor is a benign locally aggressive bone tumor of obscure origin presenting in 3rd and 4th decade of life.[1]. After distal femur and proximal tibia, distal radius happens to be the most common site of occurrence for GCT [1,2]. This site has a further distinction of having more aggressive behaviour of GCT with higher chances of recurrences and malignant transformation [3,4]. Treatment options for GCT at this site include curettage with bone grafting or cementing, en bloc excision and reconstruction with non vascular or vascular fibular autograft, osteoarticular allograft, ulnar translocation, or endoprosthesis [5-14]. The recurrence rate for primary treatment of GCT is relatively higher for curettage or extended curettage as compared to en bloc excision, making latter a more suitable and reliable option in cases showing aggressive lesions which so often is the case in distal radius $[2,3,8,15,16]$.

Reconstruction of wrist after en bloc excision of distal radius is a challenging task. Most patients are young active adults demanding cosmetically acceptable and functionally adequate wrist. We have routinely used transossiciouspamarishlongustendon and present here our experience with this procedure.

\section{Material And Method}

Ten patients with giant cell tumour of the bone at thedistal end of the radius were treated between January 2011 and January 2016 at our institution. There were 3 male and7 female patients. Their ages ranged from 25 to 45 years(average, 33.4 years). The average follow-up was 46.8 months (range, 30 to 60 months) (Table 1). All patientsunderwent staging studies that included plain radiography,computed tomography (CT), magnetic resonance imaging(MRI) and chest CT.Campanacci's staging system for giant cell tumour of the 
bone,7 was used for cortical breach. Grade I tumour had awell-marginated border of a thin rim of mature bone andthe cortex was intact or slightly thinned but not deformed.Grade II tumour had relatively well defined margins butno radio-opaque rim. Grade III tumours had fuzzy borders.

According to this system, 3 tumors were classified as StageII and 7 tumors as Stage III.If the clinical presentation and the imaging studies werecompatible with a diagnosis of a classic benign giant celltumour of the bone, the biopsy (frozen section) and surgerywere performed during the same session. In the case ofatypical clinical or radiologic presentation, either core needle or open incisional biopsy was performed andsurgery was delayed until histopathologic evaluation hadbeen completed.

The tumour was approached through dorsal approach. Wide resection was done with a safety margin of 2 to $3 \mathrm{~cm}$ based on the tumour extent in the MRI. The defect was bridged by non-vascularised proximal fibular autograft. Graft host junction was fixed by small DCP with cancellous bone graftfrom the iliac crest at the junction (Fig. 1). Reconstructionof the wrist ligaments was done via repair of the remnantsof the inferior radioulnar and radio-carpal ligaments to the graft by palmarishlongus passed through drillholes made in the graft. The proximal fibular graft was fixed with K-wire to the carpal bones and the distal ulna. Postoperatively, an above elbow cast immobilisation wasgiven in all cases for 3 months. After that, a below elbowsplint was applied until union. K-wires were removed at 8 weeks. Patients were followed-up at weekly intervals in the first month, fortnightly for the next 2 months and monthlythereafter. X-rays were taken at every visit after the 8 weeksand then every 6 weeks. The aim of the early follow-up isto detect local recurrence. The functional evaluation wasperformed using a modified system of the MusculoskeletalTumour Society.8Radiological union of the graft was assessed according toHsu et al9 with graft union defined as uninterrupted externalbony borders between the graft and the recipient bone inaddition to obscured or absent osteotomy lines.

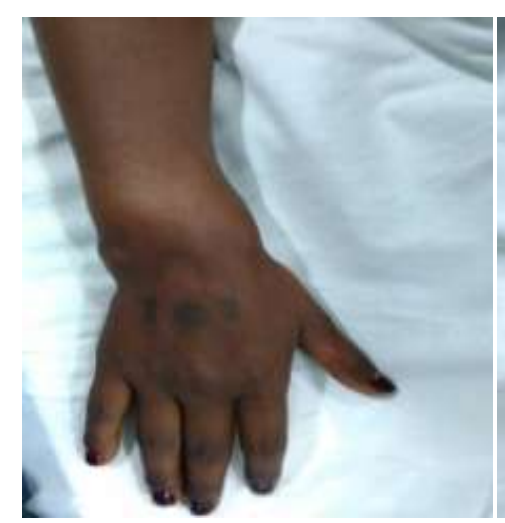

Fig-1

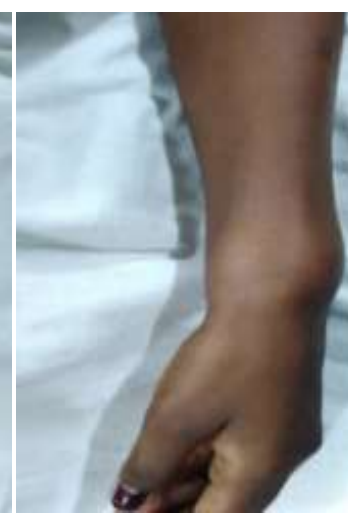

Fig-2

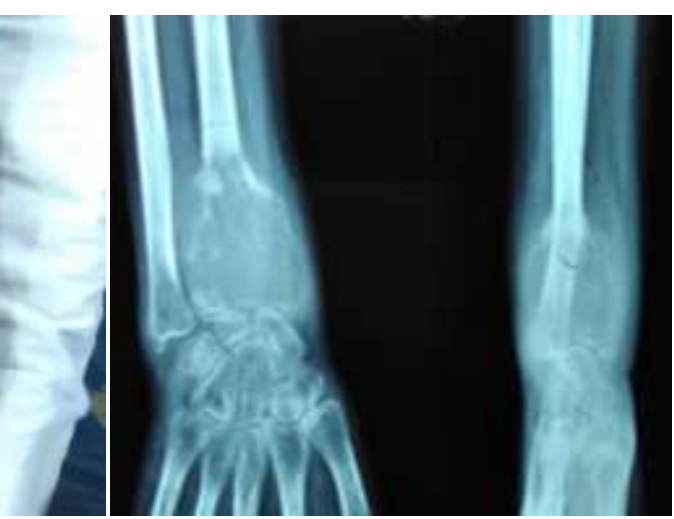

Fig-3

Fig 1,2 -clinical picture of tumor.fig -3 -shows radiological cammpanacci grade -III.

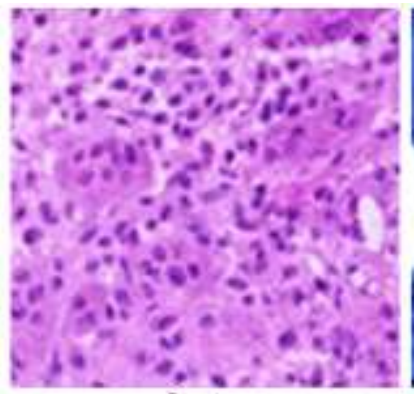

fig. 4

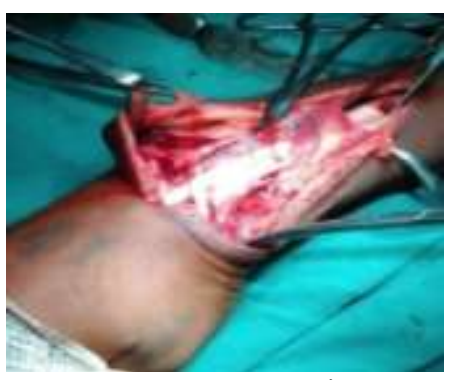

Fig-6

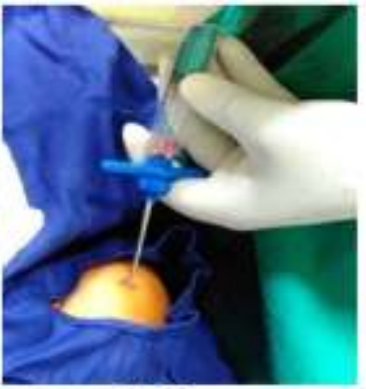

fig-5

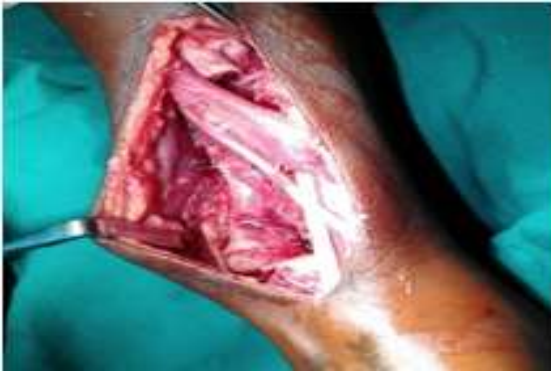

Fig-7
Fig-4 shows jamsheddi needle biopsy,

Fig-5- histopathology slide shows multiple stromal cell and giant cell.

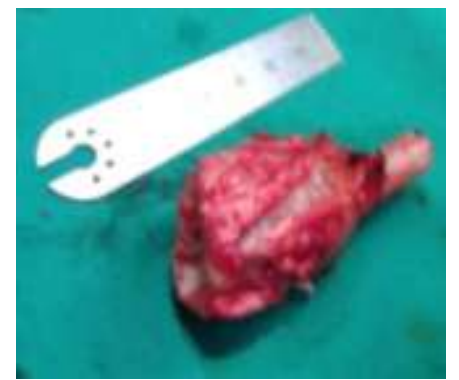

Fig-8 


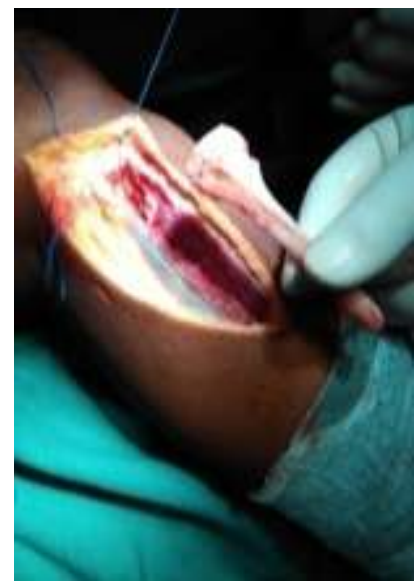

Fig-9

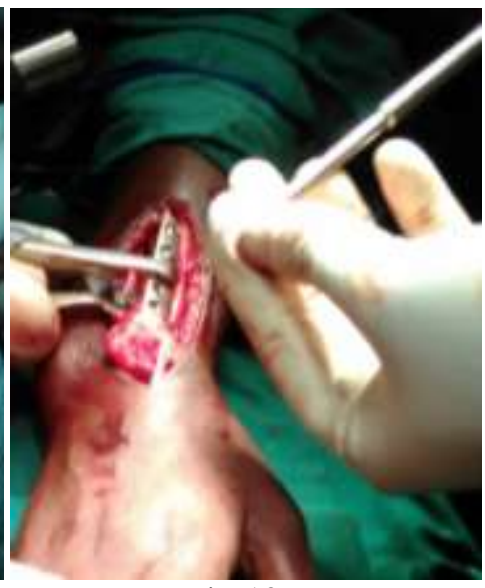

Fig-10

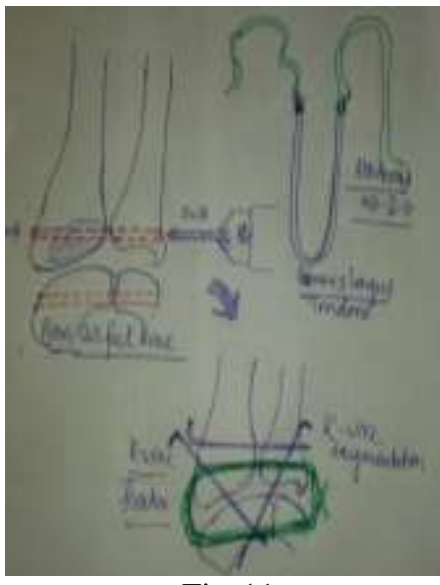

Fig-11

\section{Result}

At last follow-up, the average combined range of motion was $100.5^{\circ}$ (supination, pronation, dorsiflexion, palmar fl exion, ulnar deviation and radial deviation) with range varying from $60^{\circ}$ to $125^{\circ}$. Using the modified system of the Musculoskeletal Tumour Society, 8 the mean functional score was 93.2 (ranged from 83 to 96) (Table 1). The average union time was 7 months (range 4 to 12 months). Non-union occurred in 1 case (Case 6) and was treated by additional bone graft from the iliac crest and full union was achieved at 12 months (Fig. 2). Graft resorption occurred in another case that was managed by wrist arthrodesis using intercalary fibular graft and iliac crest bone graft (Fig. 3). Localised soft tissue recurrence was encountered in another case (Fig. 4) after 3 years andwas managed by a local excision of the nodule with the removal of the plate as the graft was fully united. This patient was followed for another 2 years and achievedgood functional results with no complications. A total of 3 secondary procedures were required. There was no caseof graft fracture, metastasis, death, local recurrence or signifi cant donor site morbidity.

Revised Musculoskeletaltumorsocietyscoreindividualpresents

\begin{tabular}{|c|c|c|c|c|c|c|c|c|}
\hline $\mathrm{S} . \mathrm{No}$ & $\mathrm{p}$ a $\mathrm{i}$ n & function & Emotionalacceptability & Handpositioning & extimity & Liftingability & $\mathrm{tot}$ a 1 & MSTSScore \\
\hline 1 & 3 & 5 & 5 & 5 & 5 & 5 & 8 & $93.33 \%$ \\
\hline 2 & 3 & 4 & 5 & 3 & 4 & 4 & 3 & $91.28 \%$ \\
\hline 3 & 4 & 5 & 5 & 5 & 5 & 4 & 8 & $93.33 \%$ \\
\hline 4 & 4 & 5 & 4 & 5 & 5 & 5 & 7 & $\begin{array}{lll}9 & 0 & \%\end{array}$ \\
\hline 5 & 4 & 4 & 5 & 5 & 5 & 5 & 7 & $\begin{array}{lll}9 & 0 & \%\end{array}$ \\
\hline 6 & 5 & 5 & 4 & 5 & 4 & 5 & 8 & $93.33 \%$ \\
\hline 7 & 4 & 4 & 5 & 5 & 5 & 5 & 2 & $\begin{array}{lll}9 & 0 & \%\end{array}$ \\
\hline 8 & 3 & 5 & 5 & 5 & 5 & 5 & 8 & $93.33 \%$ \\
\hline 9 & 5 & 5 & 5 & 5 & 5 & 3 & 8 & $93.33 \%$ \\
\hline 1 & 4 & 5 & 5 & 5 & 5 & 4 & 8 & $93.33 \%$ \\
\hline 1 & 5 & 5 & 5 & 4 & 5 & 4 & 7 & $93.33 \%$ \\
\hline $\begin{array}{ll}12 \\
\end{array}$ & 4 & 4 & 5 & 5 & 5 & 5 & 2 & $93.33 \%$ \\
\hline
\end{tabular}

Mean-27.4291.33\% 


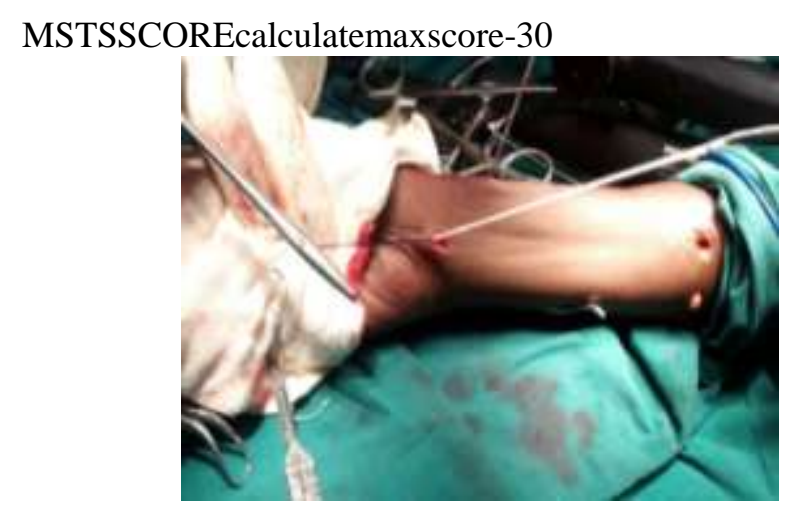

Fig-12

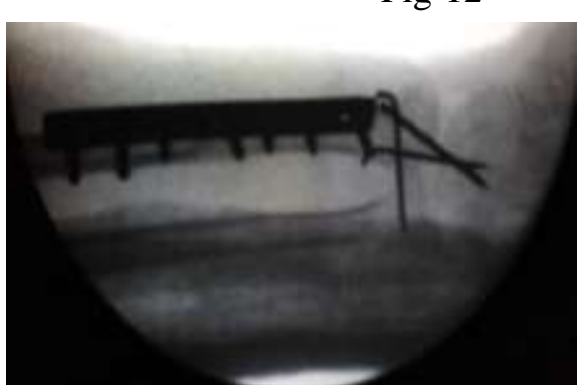

Fig14

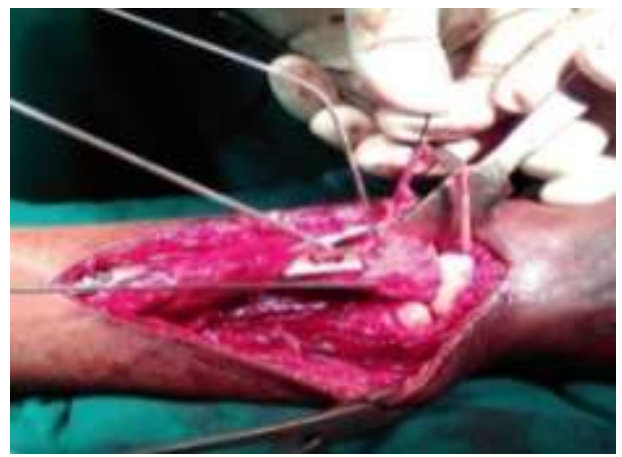

Fig-13

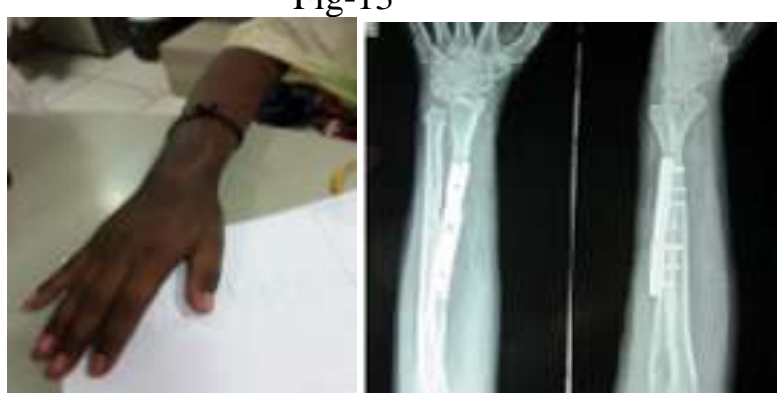

Fig-15

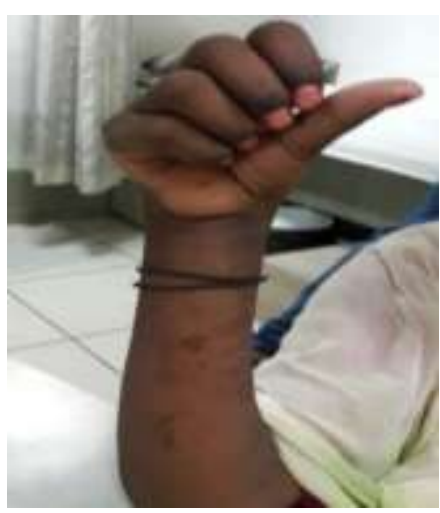

Fig-16

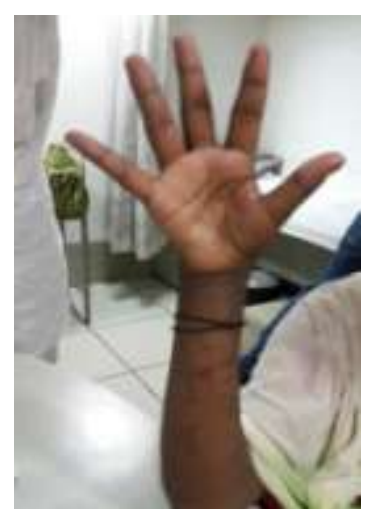

Fig-17

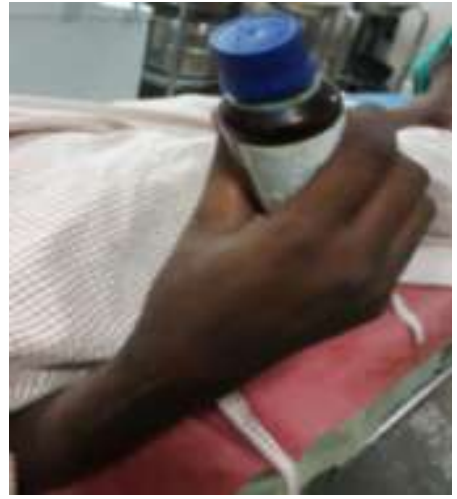

Fig-18

Fig6.7, Surgicalendblockexcision.

Fig8-Specimen

Fig-9.-Dissectionandtakingproximalfibula.

Fig10-Reimplantationofisograft.

Fig11-Blueprintofpamarishlongusaugmentation

Fig-12, 13-Palmarishlongustendongraftingandinplantation.

Fig-16, 17, 18-Goodfunctionofhand.

\section{Discussion}

GCTisachallengeforOrthopaediciansforcureaswellasrehabilitation.Thegoalsoftreatmentaretoremovethet umor,reducethechancesofrecurrenceandpreservethejointfunctionsasmuchaspossible.Thedefectcreatedbytheresect ionofthedistalradiuscanbefilledbynon-vascularizedautologousproximalfibulargraft(10-

15).Localrecurrenceandlossofjointfunctionarestillmajorproblemsfollowingsurgery.Bonegraftingorbonecementin gafterintra

lesionalcurettageofthetumorhashighlocalrecurrencerate.GCTofdistalradiusisparticularlyaggressiveandhasahighra teoflocalrecurrence $(7,8)$.AwideresectionofthedistalradiusGCTwhenthetumorbreaksthroughthecortexondorsaland volarsideshasbeenrecommendedbyearlierworkers $(19,20)$. Resectionofdistalradiusandreconstructionwithautologo usnonvascularizedfibulaoffersseveraladvantageslikemorecongruencyofcarpaljoint,rapidincorporationasautograft andeasyaccessibilitywithoutsignificantdonorsitemorbidity.Structuralchangeisalsominimal.Moreover,immunogen icreactionsareabsentandbonebankingfacilitiesorgraftmatchingproceduresarenotrequired.Usingvascularizedfibular 
grafttospeedupthehealingathost-

graftjunctionandreducingtheperiodofimmobilizationarereportedtobeinconclusive(18).Theoperatingtimeforvascul arizedfibulargraftoftenreaches12-

14hoursandrequiressacrificeoftwomajorvessels.Dissectiontoobtainthefibulaanditsvascularpedicleandtheisolation ofitsrecipientvesselsrequiresmeticulousattention,sophisticatedinfrastructure,skillandprolongedoperatingtimehave madeitsuselimited(17).

\section{Discussion}

GCT is a challenge for Orthopaedicians for cure as well as rehabilitation. The goals of treatment are to remove the tumor, reduce the chances of recurrence and preserve the joint functions as much as possible. The defect created by the resection of the distal radius can be filled by non-vascularizedautologous proximal fibular graft (10-15). Local recurrence and loss of joint function are still major problems following surgery. Bone grafting or bone cementing after intra-lesional curettage of the tumor has high local recurrence rate. GCT of distal radius is particularly aggressive and has a high rate of local recurrence $(7,8)$. A wide resection of the distal radius GCT when the tumor breaks through the cortex on dorsal and volar sides has been recommended by earlier workers $(19,20)$. Resection of distal radius and reconstruction with autologous non-vascularized fibula offers several advantages like more congruency of carpal joint, rapid incorporation as autograft and easy accessibility without significant donor site morbidity. Structural change is also minimal. Moreover, immunogenic reactions are absent and bone banking facilities or graft matching procedures are not required. Using vascularized fibular graft to speed up the healing at host-graft junction and reducing the period of immobilization are reported to be inconclusive (18). The operating time for vascularized fibular graft often reaches 12-14 hours and requires sacrifice of two major vessels. Dissection to obtain the fibula and its vascular pedicle and the isolation of its recipient vessels requires meticulous attention, sophisticated infrastructure, skill and prolonged operating time have made its use limited (17).

\section{Conclusion}

Hence, considering all factors, the treatment of distal radius GCT with non-vascularised fibular graft is reliable practical technique, which gives optimal result, and is useful in preserving the movements and functions as well as stability of the wrist.

\section{Reference}

[1]. Dahlin DC, Cupps RE, Johnson EW. J Giant Cell Tumour: A study of 195 cases. Cancer 1970;25:1061-70.

[2]. Eckardt JJ, Grogan TJ. Giant cell tumour of bone. ClinOrthop 1986;204:45-58.

[3]. Khalil el SA, Younis A, Aziz SA, Shahawy M. Surgical management for Giant cell tumor of bones. J Egypt NatlCanc Inst 2004;16:145-52.

[4]. Chalidis BE, Dimitriou CG. Modified ulnar translocation technique for the reconstruction of giant cell tumor of the distal radius. Orthopedics 2008;31:608.

[5]. Rastogi S, Prasanth I, Khan SA, Trikha V, Mittal R. Giant cell tumour of bone: Is curettage the answer? Ind J Orthop 2007;41:10914.

[6]. Campanacci M, Baldini N, Boriani S, Sudanese A. Giant cell tumour of bone. J Bone joint Surg Am 1987;69:106-14

[7]. Getilis S, Mallin BA, Piaseccki P, Turner F. Intralesional excision compared with en bloc resection for giant cell tumour of bone. J Bone Joint Surg Am 1993;75:1648-55.

[8]. Vander Griend RA, Funderburk CH. The treatment of giant cell tumour of distal part of the radius. J Bone Joint Surg Am 1993;75:899-908.

[9]. Walthar M. Resection de extremiteinferieure du radius pour osteosarcomageffe de I extremitesuperiuete du perone. Sac Chir Par Bull Mem 1911:37:739-47.

[10]. Murray JA, Schlafly B. Giant cell tumours in the distal end of the radius. Treatment by resection and autograftinterpositionalarthrodesis. J Bone Joint Surg Am 1986;68:687-94.

[11]. Goni V, Gill SS, Dhillon MS, Nagi ON. Reconstruction of massive skeletal defects after tumour resection. Ind J Orthop $1992 ; 26: 13-6$

[12]. Aithal VK, Bhaskaranand K. Reconstruction of distal radius following excision of giant cell tumour. IntOrthop 2003;27:110-3.

[13]. Harris WR, Lehmann EC. Recurrent giant cell tumour after en bloc excision of distal radius and fibular autograft replacement. J Bone Joint Surg Br 1983;65:618-20.

[14]. Parrish FF. Treatment of bone tumors by total excision and replace mentwith massive autologous and homologous grafts. J Bone Joint Surg Am1966;48:968-90.

[15]. Pho RWH. Malignant giant cell tumor or the distal end or the radiustreated by a free vascularizedfibular transplant. J Bone Joint Surg Am1981;63:877-84.

[16]. Unni KK. General aspects and data on 11087 cases. In: Dahlins' BoneTumors. 5th ed. Philadelphia: Lippincott-Raven Publishers, 1996:263-

[17]. Mund DF, Yao L, Fu YS, Eckardt JJ. Case report 826: physiologicalresorption of allograft simulating recurrent giant cell tumor. SkeletalRadiol 1994;23:139-41.

[18]. Starr DE. Congenital absence of radius; method of surgical correction.J Bone Joint Surg 1945;27:572.

[19]. Kocher MS, Gebhardt MC, Mankin HG. Reconstruction of the distalaspect of the raduis with the use of osteoarticular allograft after excisionof skeletal tumour. J Bone Joint Surg 1998;407:419.

[20]. Murray JA, Schlafl y B. Giant cell tumors in the distal end of the radius.Treatment by resection and fibularautograftinterpositionalarthroplasties.J Bone Joint Surg Am 1986;687:94

[21]. Chiang IM, Chen TH, Shih LY, Lo WH. Nonvascularised proximal fibularautograft to treat giant cell tumors of the distal radius. Zhonghua Yi Xu 